\title{
Design of Automatic Hand Sanitizer System Compatible with Various Containers
}

\author{
Juhui Lee ${ }^{1,2,3}$, Jin-Young Lee ${ }^{2}$, Sung-Min Cho ${ }^{2}$, Ki-Cheol Yoon ${ }^{2,3}$, Young Jae Kim ${ }^{1,2,3}$, Kwang Gi Kim ${ }^{1,2,3,4}$ \\ 'Department of Biomedical Engineering, College of Health Science, Gachon University, Incheon, Korea \\ ${ }^{2}$ Medical Devices R\&D Center, Gachon University Gil Hospital, Incheon, Korea \\ ${ }^{3}$ Pre-medical Course, College of Medicine, Gachon University, Incheon, Korea \\ ${ }^{4}$ Department of Health Sciences and Technology, Gachon Advanced Institute for Health \& Sciences and Technology (GAIHST), Gachon University, Incheon, \\ Korea
}

Objectives: Demand for hand sanitizers has surged since the coronavirus broke out and spread around the world. Hand sanitizers are usually applied by squirting the sanitizer liquid when one presses a pump with one's hand. This causes many people to come into contact with the pump handle, which increases the risk of viral transmission. Some hand sanitizers on the market are automatically pumped. However, because sanitizer containers and pump devices are designed to be compatible only between products produced by the same manufacturer, consumers must also repurchase the container for the liquid if they replace the hand sanitizer. Therefore, this paper suggests the design of an automatic hand sanitizer system compatible with various sanitizer containers. Methods: An automatic hand sanitizer system was designed, which will be presented in two stages describing the instrument structure and control parts. This work focused on using the elasticity of pumps and improving people's access to devices. Results: We have designed an automatic hand sanitizer system that is compatible with various containers. When one moves one's hand close to the device sensor, the hand sanitizer container is pumped once. Conclusions: The automatic hand sanitizer device proposed in this paper is ultimately expected to contribute to contactless hand disinfection in public places and virus infection prevention. Additionally, it is economical and eco-friendly by decreasing waste emissions.

Keywords: Automatism, Internet of Things, Hand Sanitizers, Infrared Rays, Motor Skills

Submitted: June 30, 2020

Revised: July 19, 2020

Accepted: July 20, 2020

\section{Corresponding Author}

Kwang Gi Kim

Department of Biomedical Engineering, College of Health Science, Gachon University, 1198, Guwol-dong, Namdong-gu, Incheon 21565, Korea. Tel: +82-32-820-4036, E-mail: kimkg@gachon.ac.kr (https://orcid.org/0000-0001-9714-6038)

This is an Open Access article distributed under the terms of the Creative Commons Attribution Non-Commercial License (http://creativecommons.org/licenses/by$\mathrm{nc} / 4.0 /$ ) which permits unrestricted non-commercial use, distribution, and reproduction in any medium, provided the original work is properly cited.

(c) 2020 The Korean Society of Medical Informatics

\section{Introduction}

Demand for hand sanitizers has surged as the coronavirus broke out and spread around the world [1-3]. Alcohol gel hand sanitizers are usually applied by squirting the sanitizer liquid when one presses a pump with one's hand [4]. This causes many people to come into contact with the pump handle, which increases the risk of viral transmission. Pressing the pump handle is bothersome, and many pass by without disinfecting their hands. Moreover, each person presses the pump handle differently, making it difficult to predict the amount of use and to manage refills and replacements. For this reason, the actual use of hand sanitizers is reduced, which does not help prevent spread of the virus [5]. 


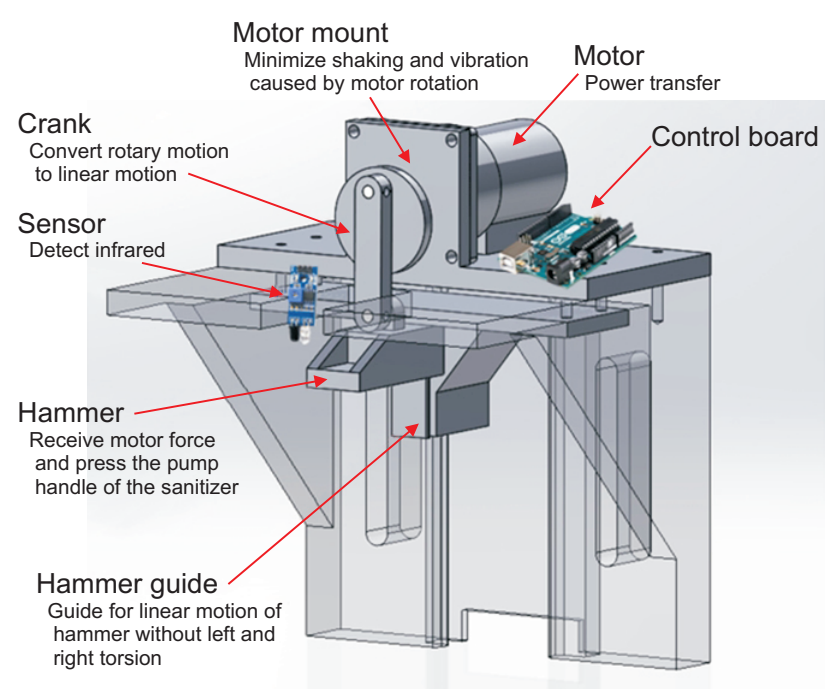

Figure 1. Parts of the hand sanitizer device drive mechanism.

Some hand sanitizers on the market are automatically pumped. However, because sanitizer containers and pump devices are designed to be compatible only between products produced by the same manufacturer, consumers must also repurchase the container for the liquid if they replace the hand sanitizer [6,7]. It is not economical and it has a negative impact on the environment by increasing waste emissions. In addition, some users may think that it is a hassle to buy a hand sanitizer-containing device-compatible again, so they pour other hand sanitizers into previously used containers and reuse them. However, sanitizers that come directly into contact with the human body are classified as medicines or non-medical products, and they are safest to use in original containers [8].

In this paper, the design of an automatic hand sanitizer system compatible with various sanitizer containers is presented. The device was manufactured with polylactic acid (PLA) using a 3D printer.

\section{Methods}

The automatic hand sanitizer system design will be presented in two stages, the instrument structure and control parts. This work focused on using the elasticity of pumps and improving people's access to devices.

\section{Structure Design}

As seen in Figure 1, the motor, control board, and sensor are located at the top of the automatic hand sanitizer device. The device operates by converting the rotary motion of the DC motor to linear motion through the crank and pressing the pump handle of the hand sanitizer container with the ham-

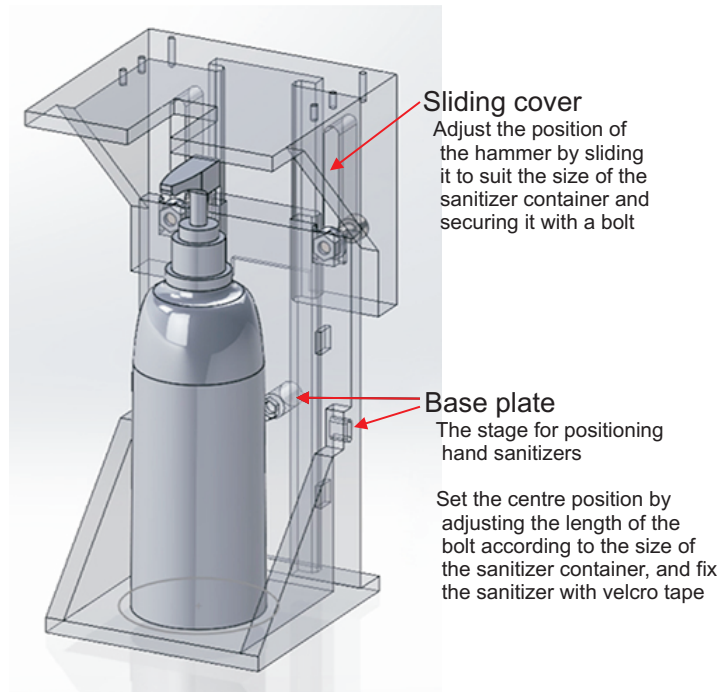

Figure 2. Operating method of instruments for compatibility with various sanitizer containers.

mer.

The motor mount minimizes shaking and vibration caused by operation of the motor, and the hammer guide allows the hammer to move vertically without distortion in the left and right directions.

As seen in Figure 2, the sliding cover adjusts the position of the hammer by sliding it to suit the size of the sanitizer container and securing it with a bolt. We set a base plate at the center position by adjusting the length of the bolt to fit the size of the sanitizer container and fix the sanitizer with Velcro tape.

The overall size of the automatic hand sanitizer device is $140 \mathrm{~mm} \times 130 \mathrm{~mm} \times 330 \mathrm{~mm}$, and it weighs less than 1.27 $\mathrm{kg}$ not including the liquid container. The case in this system was manufactured with PLA using a 3D printer for a lightweight and easy manufacturing process. The front view of the device is shown in Figure 3.

\section{Controller Design}

As seen in Figures 4 and 5, the Automatic hand sanitizer device consists of a power supply, sensor, board, motor controller, and motor. The power supply provides voltage and current for the operation of the motor and board, and its power source is a battery. Through a regulator, the board converts $9 \mathrm{~V}$ power from the power supply to $5 \mathrm{~V}$ and applies it to the sensor [9]. Infrared (IR) sensors beam infrared rays from the light-emitting unit, and it is reflected from the surface of the object and absorbed at a light-receiving unit. The motor controller consists of an $\mathrm{H}$-Bridge motor driver L293D, which can control the motor according to the input 


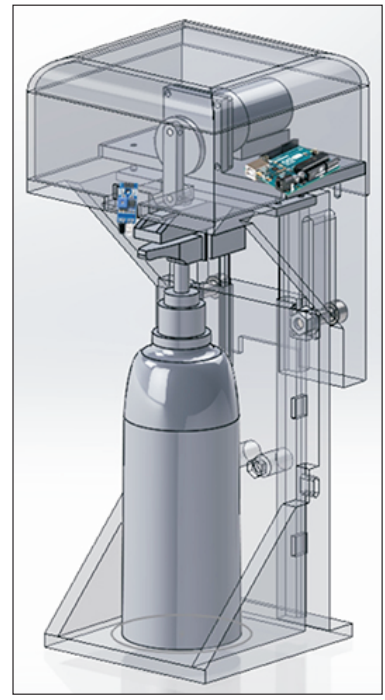

Figure 3. Structure foreground.



Figure 4. Block diagram of controller circuit.

value of the sensor. The DC motor provides a major force to the device and is controlled by the motor driver.

As shown in Figure 6A, the setMotor function is specified to control the L293D and the motor. The setMotor function targets the L293D, which sets the speed and direction of the DC motor.

Figure $6 \mathrm{~B}$ shows the running code for operating the device. When the IR sensor detects an object, the IR sensor's light turns on, and the DC motor does about one turn of motion considering the elasticity of the sanitizer container's pump and the motor's rated number of rotations of $185 \mathrm{rpm}$ (revolutions per minute). The device can operate regardless of the direction of motor operation. With the motor's running power, the hammer moves vertically once and presses the pump handle of the disinfectant container. When the IR sensor no longer detects an object, the IR sensor light turns off and the DC motor ceases operation.

\section{Results}

We have designed an automatic hand sanitizer system that is compatible with various containers. When one moves one's hand close to the device sensor, the hand sanitizer container is pumped once. Figure 7A-C show actual images of the pro-

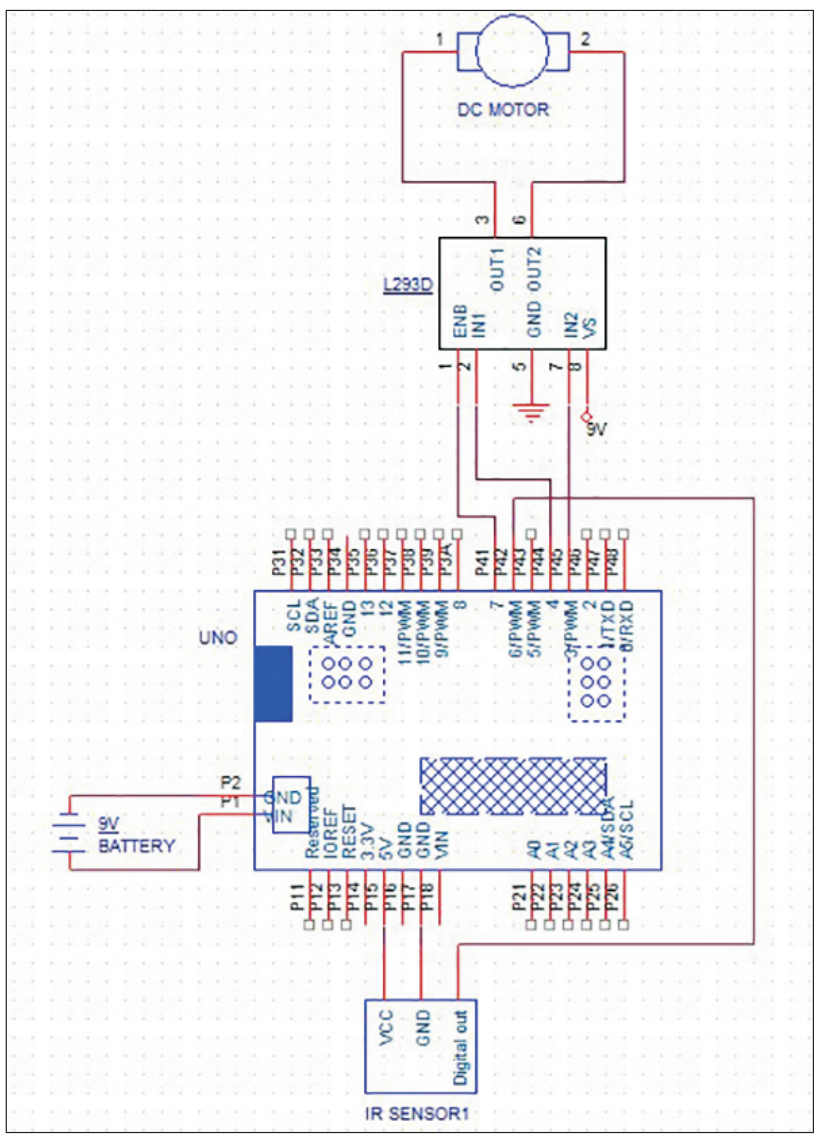

Figure 5. Controller circuit.

posed device.

\section{Conclusion}

Hand sanitizers usually operate by squirting sanitizer liquid when one presses a pump with one's hand. Some hand sanitizers on the market are automatically pumped. However, sanitizer containers and pump devices are designed to be compatible only between products produced by the same manufacturer.

To address this problem, we have designed an automatic hand sanitizer system that is compatible with various containers. With the proposed device, it is possible to avoid many people coming into contact with the pump handle, thus preventing fomite viral transmission and making the use of hand sanitizer much more convenient. Moreover, the system squirts a certain amount of hand sanitizer at all times, making it easy to manage refills and replacement. Furthermore, it can operate compatibly with various designs of sanitizer containers, so consumers do not need repurchase a container for the liquid if they replace the hand sanitizer. Thus, it is economical and eco-friendly by decreasing waste 




Figure 6. Controller algorithm: (A) motor set and (B) running code.

emissions. The automatic hand sanitizer device proposed by this paper is ultimately expected to contribute to contactless hand disinfection in public places and virus infection prevention.

\section{Conflict of Interest}

Kwang Gi Kim is an editor of Healthcare Informatics Research; however, he did not involve in the peer reviewer selection, evaluation, and decision process of this article. Otherwise, no potential conflict of interest relevant to this article was reported.


Figure 7. Fabrication of the structure: (A) front view, (B) right side view, and (C) rear view.

\section{Acknowledgments}

This research was supported by the Ministry of Science and ICT, Korea, under the Information Technology Research Center support program (No. IITP-2020-2017-0-01630) supervised by the Institute for Information \& communications Technology Promotion (IITP), the GRRC program of Gyeonggi province (No. GRRC-Gachon2020(B01), AI-based Medical Image Analysis) and the Gachon University Gil Medical Center (No. FRD2019-11). In addition, the research project work was supported by the Gachon University (No. 2019-0303).

\section{ORCID}

Juhui Lee (https://orcid.org/0000-0002-9656-0605) Jin-Young Lee (https://orcid.org/0000-0003-4691-9031) Sung-Min Cho (https://orcid.org/0000-0001-5404-2407) Ki-Cheol Yoon (https://orcid.org/0000-0002-0735-5846) Young Jae Kim (https://orcid.org/0000-0003-0443-0051) Kwang Gi Kim (https://orcid.org/0000-0001-9714-6038)

\section{References}

1. Wang C, Horby PW, Hayden FG, Gao GF. A novel coronavirus outbreak of global health concern. Lancet 2020;395(10223):470-3.

2. Wu F, Zhao S, Yu B, Chen YM, Wang W, Song ZG, et al. A new coronavirus associated with human respiratory disease in China. Nature 2020;579(7798):265-9.

3. Lai CC, Shih TP, Ko WC, Tang HJ, Hsueh PR. Severe acute respiratory syndrome coronavirus 2 (SARSCoV-2) and coronavirus disease-2019 (COVID-19): the epidemic and the challenges. Int J Antimicrob Agents 
2020;55(3):105924.

4. Spears L, inventor. Decorative Liquid Soap Container (DLSC). United States patent application 12/291,938. 2010 Mar 25.

5. Bloomfield SF, Aiello AE, Cookson B, O'Boyle C, Larson EL. The effectiveness of hand hygiene procedures in reducing the risks of infections in home and community settings including handwashing and alcohol-based hand sanitizers. Am J Infect Control 2007;35(10):S27-S64.

6. Cittadino AM, Byl CC, Wilcox MT, Paal AP, Budz GD, Cornell RW, inventors. Pumping dispenser. United States patent US 8,261,950. 2012 Sep 11.
7. Iseri M, Malina Y, Hardman J, inventors. Dispenser for hand sanitizer. United States patent US 9,060,655. 2015 Jun 23.

8. Ministry of Food and Drug Safety. Introduction of nonmedical products [Internet]. Sejong, Korea: Ministry of Food and Drug Safety; c2020 [cited at 2020 Aug 4]. Available from: https://www.mfds.go.kr/wpge/m_637/ de0508011001.do.

9. Arduino [Internet]. Somerville (MA): Arduino; c2020 [cited at 2020 Aug 4]. Available from: https://www.arduino.cc/. 